\title{
Comunicar la disidencia. Un recorrido por tres escisiones de Montoneros en los setentas
}

\author{
Communicate the dissidence. A study on three internal dissidences of \\ Montoneros during the seventies
}

Daniela Slipak*

\begin{abstract}
Resumen: Desde una sociología de las identidades políticas, el artículo analiza tres disidencias de la organización argentina Montoneros surgidas en momentos completamente disímiles y con características diversas, los "Montoneros Columna José Sabino Navarro" de 1972, la "Juventud Peronista Lealtad" de 1974, y el "Peronismo Montonero Auténtico" de 1979. Se recorren sus prácticas, documentos y publicaciones, con el objeto de realizar, aunque sea de forma exploratoria, tres aportes: a) efectuar una contribución más a los crecientes estudios sobre las formas de comunicación de los grupos insurgentes latinoamericanos de la segunda mitad de siglo $\mathrm{XX}$; b) echar luz sobre algunas de las rupturas que sufrió Montoneros, tratando de elaborar argumentos generales sobre los procesos de constitución de las disidencias montoneras; y c) indagar el modo en que la Conducción Nacional y el resto del espacio montonero gestionaron las críticas, impugnaciones y rupturas, y sostuvieron sus mecanismos disciplinarios.
\end{abstract}

Palabras clave: Disidencias, Montoneros, identidad, comunicación

\begin{abstract}
From a political identities sociology, this paper analyzes three dissidences of the argentinian Montoneros organization wich emerged in completely dissimilar moments and with different characteristics. These dissidences are "Montoneros Columna José Sabino Navarro" 1972, the "Juventud Peronista Lealtad" in 1974 and the "Peronismo Montonero Auténtico" in 1979. This paper studies these dissidences practices, documents and publications in order to carry out three contributions: a) to make a contribution on the ways of communication of the latinamerican insurgent groups of the second half of the twenthieth century; b) to shed light on some of the ruptures that Montoneros suffered in it interior, trying to elaborate general arguments about the processes of constitution of the Montoneros dissidences; and c) to investigate the way in wich the National Direction and the rest of the Montoneros group managed the internal criticisms, challenges and ruptures, and, at the same time, sustained disciplinary mechanisms.
\end{abstract}

Keywords: Dissidences, Montoneros, identity, communication.

\footnotetext{
* Argentina. Doctora en Estudios Políticos (EHESS-UBA). Investigadora Conicet, con sede en el IDAESUNSAM, danielaslipak@ hotmail.com. Agradezco a Julián Melo los comentarios realizados a una versión preliminar del texto.
} 


\section{Introducción}

La militancia articulada alrededor de la organización Montoneros no fue lineal ni homogénea. Existieron numerosas discusiones y tensiones a lo largo de la década de existencia del grupo, desde el gobierno de la autodenominada Revolución Argentina hasta las últimas experiencias atravesadas por el exilio de su Conducción Nacional. En algunos casos, estas rispideces se tradujeron en la conformación de espacios de pertenencia alternativos, que variaron en la cantidad de adherentes, en su visibilidad pública, y en el tipo de actividades y de circuitos territoriales. Fueron cinco los grupos disidentes más importantes. En primer lugar, Montoneros Columna José Sabino Navarro, que surgió en 1972 cuestionando las alianzas de la Conducción Nacional con otros sectores del Movimiento Peronista y denunciando su sobrevaloración de la práctica armada. En segundo lugar, el grupo Montoneros Columna de Recuperación Cooke-Pujadas de 1974, que criticó a la cúpula montonera por sus alianzas con otros actores del Movimiento, y sostuvo que los sectores populares debían organizarse de manera alternativa al liderazgo de Perón. En tercer lugar, la Juventud Peronista Lealtad de comienzos de 1974, que proclamó la defensa del proyecto de Perón. En cuarto lugar, ya durante el autodenominado Proceso de Reorganización Nacional, el Peronismo Montonero Auténtico, que rompió en 1979 en el exilio y con la militancia marcadamente disminuida por la feroz represión militar. Finalmente, se separó el grupo Montoneros 17 de octubre. Fue ésta la disidencia que terminó de desarticular la organización, llevándose buena parte de los militantes que quedaban en sus filas. Tras ella, se decretó el cese definitivo de la "lucha armada".

Si bien fue distinta la respuesta de la "organización madre" ante cada ruptura, en sintonía con sus cambios estructurales en el marco de la coyuntura nacional, lo cierto es que las disidencias no sólo fueron cuestionadas sino también ocultadas y negadas. A pesar de que dichas escisiones buscaron con insistencia comunicar sus prácticas, ideas y decisiones a través de documentos y de prensa periódica, Montoneros intentó invisibilizar sus voces. En términos de una sociología de las identidades políticas, preocupada por indagar las lógicas de constitución y funcionamiento de las pertenencias y solidaridades estables, ${ }^{1}$ podría afirmarse que antes que otorgar el espacio para el desarrollo de los desacuerdos en las tramas internas, en Montoneros se buscó velarlos, clausurando también su escenificación una vez producidos los quiebres. En otras palabras, el mecanismo de gestión de las diferencias consistió, precisamente, en obturar su despliegue.

En cierto punto, algo de esta tendencia al desdibujamiento de las diferencias se reproduce en la literatura que hoy circula sobre aquellos años. Son pocos los trabajos que abordan las discrepancias al interior de la organización, y menos los que se abocan a estudiar detalladamente los grupos disidentes. Entre ellos, se cuentan los testimoniales ${ }^{2}$ y

\footnotetext{
${ }^{1}$ Una definición de identidad política, que recoge distintas tradiciones de discusión en la teoría y la sociología políticas, puede verse en Gerardo Aboy Carlés, Las dos fronteras de la democracia argentina. La reformulación de las identidades políticas de Alfonsín a Menem, Rosario, Homo Sapiens, 2001.

${ }^{2}$ Norberto Ivancich y Mario Wainfeld, "El gobierno peronista 1973-1976: los Montoneros (tercera parte)" en Revista Unidos, 7/8, Buenos Aires, 1985; Luis Rodeiro, Fantasías de bandoneón (una disidencia montonera), Buenos Aires, Ediciones de la Cortada, 1996; Mario Aiscurri, iQue vivan los perejiles!, Buenos Aires, Catálogos, 2003; Luis Rodeiro, “El 'Documento Verde': la primera crítica a Montoneros desde Montoneros”,
} 
los académicos ${ }^{3}$. Aunque resultan sumamente valiosos, por la información que aportan como por las preguntas analíticas que formulan, guardan silencio sobre el interrogante más general referido a las lógicas de constitución de las disidencias a lo largo del derrotero montonero, que contempla no sólo las particularidades de cada ruptura sino también las respuestas de su "organización madre". Este interrogante supone, en términos teóricos, llevar la mirada a los distintos mecanismos que los grupos políticos despliegan para tramitar las divergencias en el marco de una identidad, es decir, concentrarse en las disímiles formas de gestionarlas dentro de las fronteras de lo común. En breve, implica preguntarse por el estatus que cada ámbito otorga a la diferencia al interior de la comunidad. Al respecto, resulta llamativo que si bien la organización creó dos cuerpos normativos disciplinarios (las "Disposiciones sobre la Justicia Penal Revolucionaria" y el "Código de Justicia Penal Revolucionario") y desplegó numerosas sanciones para clausurar las prácticas disímiles al patrón de conducta exigido, todavía no existen trabajos exhaustivos -esto es, que excedan casos puntuales- sobre la cuestión. ${ }^{4}$

Desde una preocupación teórica referida a los procesos de conformación y funcionamiento de las identidades políticas, por tanto, en el presente artículo busco realizar, aún de manera exploratoria, tres aportes: a) efectuar una contribución más a los crecientes estudios sobre las formas de comunicación de los grupos insurgentes latinoamericanos de la segunda mitad del siglo $\mathrm{XX} ;^{5}$ b) echar luz sobre algunas de las rupturas que sufrió Montoneros, tratando de elaborar argumentos generales sobre los procesos de constitución de las disidencias montoneras; y c) indagar el modo en que la Conducción Nacional y el resto del espacio gestionaron las críticas, impugnaciones y rupturas, y sostuvieron sus mecanismos disciplinarios. Para ello, recorreré documentos y publicaciones de tres de las

Lucha Armada en la Argentina, 6, Buenos Aires, 2006, 56-61; Luis Rodeiro, Textos Viscerales, Buenos Aires, Caterva, 2015; José Amorín, Montoneros: la buena historia, Buenos Aires, Catálogos, 2006; Alejandro Peyrou, "Lealtad", Lucha Armada en la Argentina, Anuario, Buenos Aires, 2010, 44-63; Aldo Duzdevich, Norberto Raffoul y Rodolfo Beltramini, La Lealtad. Los Montoneros que se quedaron con Perón, Buenos Aires, Sudamericana, 2015.

3 Ana Soledad Montero, "Héroes, ortodoxos, disidentes y traidores. Los avatares de la Juventud Peronista Lealtad (1973-1976)", Red interdisciplinaria de estudios sobre historia reciente, 2009, 10-14; Javier Salcedo, Los montoneros del barrio, Buenos Aires, Eduntref, 2011; Leandro Inchauspe y Ana Noguera, "La Columna José Sabino Navarro: un acercamiento a la militancia armada peronista en la córdoba de los '70 a través de fuentes orales", I Workshop Interuniversitario "Partidos políticos y elecciones en espacios regionales y provinciales”, Resistencia, 2011; Mariana Pozzoni, “"Leales' y 'traidores': La experiencia de disidencia de la Juventud Peronista Lealtad (1973-1974)", Nuevo Mundo Mundos Nuevos [En ligne], Questions du temps présent, mis en ligne le 03 juin 2013, consulté le 24 octobre 2017; Leandro Inchauspe y Ana Noguera, "“Ya éramos en origen algo distinto'. La Columna Sabino Navarro y su desarrollo en la Córdoba de los '70", Revista Estudios, 34, Córdoba, 2015, 29-49; Daniela Slipak, Las revistas montoneras. Cómo la organización construyó su identidad a través de sus publicaciones, Buenos Aires, Siglo XXI, 2015; Luciana Seminara, Bajo la sombra del ombú. Montoneros Sabino Navarro, historia de una disidencia, Buenos Aires, Imago Mundi, 2015.

${ }^{4}$ Una excepción a esta tendencia la encontramos en el trabajo de Laura Lenci, "Justicia, política y violencia. Un análisis de los cuerpos normativos montoneros 1972-1975", ponencia presentada en las II Jornadas de "Partidos Armados en la Argentina de los Setenta", UNSAM, 2008.

${ }^{5}$ Para un exhaustivo estado de la cuestión sobre la temática, véase el artículo de Eudald Cortina Orero que integra este dossier. 
escisiones, surgidas en momentos completamente disímiles y con características diversas, los Montoneros Columna José Sabino Navarro, la Juventud Peronista Lealtad y el Peronismo Montonero Auténtico. Explicitaré las formas de comunicación y escenificación pública de estos grupos que desplegaron redes de militancia alternativas, y las gestiones desplegadas por su "organización madre". 6

\section{Los Montoneros Columna José Sabino Navarro}

Este espacio constituyó la primera disidencia montonera. Se conformó tempranamente, a partir de una serie de críticas realizadas a la cúpula dirigente en los años iniciales de la organización. Los cuestionamientos fueron efectuados por un conjunto de militantes (Ignacio Vélez, Carlos Soratti, Luis Losada, Jorge Cottone, Antonio Riestra, Carlos Figueroa, José Fierro y Luis Rodeiro, entre otros) que habían sido encerrados en el régimen carcelario de la autodenominada Revolución Argentina. Con el paso de los meses, las impugnaciones tuvieron eco en un sector de la organización en Córdoba, la Columna Sur, que si bien se había unido a grupos que creían en esquemas más "foquistas", antiguamente había estado vinculada a la Agrupación Peronista Lealtad y Lucha, que desplegaba actividades en universidades, barrios, fábricas y sindicatos, y, sólo en menor medida, intervenciones armadas. Además, los planteos disidentes tuvieron buena recepción en un sector de la militancia de Rosario, también en la Columna Sur. Con estas redes vinculadas al trabajo territorial, y una vez liberados los presos gracias a la amnistía otorgada por el presidente Héctor Cámpora a inicios de su corto gobierno, fue que se conformó Montoneros Columna José Sabino Navarro. La negativa de la Conducción Nacional a discutir la autocrítica contribuyó a ampliar el espacio. Al tiempo, la disidencia resolvió borrar la alusión a Montoneros de su nombre, pasando a denominarse Columna José Sabino Navarro. De todos modos, sostuvo que seguía formando parte de la Tendencia Revolucionaria Peronista en sentido amplio, y cuestionó el "alternativismo puro". Nunca creyó que Montoneros fuera un adversario: "reconocemos en los compañeros Montoneros más allá de las diferencias- a compañeros honestamente revolucionarios con los cuales discrepamos pero que jamás podemos verlos como enemigos". ${ }^{7}$

La importancia cualitativa y cuantitativa de la disidencia fue variando, y llegó a tener considerable presencia en Córdoba y Rosario, y, en menor medida, en Tucumán y Buenos Aires. Desarrollaron redes en espacios sindicales, barriales y universitarios. De hecho, a través de la agrupación "Peronismo Descamisado" desplegaron los frentes barrial y sindical en Córdoba. Asimismo, tuvieron incidencia en el cordón industrial del Gran Rosario. Aunque no abandonaron la idea del circuito armado, éste fue pequeño, y se ocupó fundamentalmente de obtener armas y dinero. A diferencia de la lógica de Montoneros,

\footnotetext{
${ }^{6}$ He seleccionado estas tres disidencias debido a que responden a momentos disímiles de la organización y en conjunto permiten recorrer, a través de escenas específicas, casi la totalidad del derrotero montonero.

7 “Cartilla para militantes. N 1", Militancia, 20, 25/10/73, 44. Testimonios que me brindaron ex militantes, 24/11/2011 y 08/06/2011. Véase también Rodeiro, op. cit., 1996; Seminara, op. cit.; y Lucas Lanusse, Montoneros. El mito de sus 12 fundadores, Buenos Aires, Vergara, 2007.
} 
eran los jefes de los espacios políticos, y no los del grupo clandestino, quienes tomaban las decisiones del conjunto. ${ }^{8}$

Ahora bien, el espacio disidente, primero desde la cárcel y luego durante los gobiernos peronistas del periodo, se ocupó de comunicar, a través de formas diversas, las razones de su ruptura. No abandonó las armas, pero buscó, al igual que lo hacía la organización con su prensa, articular un relato público sobre su historia y sus proyectos. En 1971, se publicaron tres artículos: "El peronismo hoy" y "Algunas aclaraciones", en el mes de julio; y "Bases y proyecto revolucionario peronista", en septiembre. Los dos primeros en la revista Nuevo Hombre. ${ }^{9}$ Un poco más adelante, a mediados de 1972, apareció el "Documento Verde" (por el color de la tapa de la copia mimeografiada), consistente en una extensa crítica hacia Montoneros. Todavía en este escrito se explicitaba la voluntad de permanecer en la organización, aunque se afirmaba la necesidad de dar un debate a su interior. Dicha pretensión se desdibujó ya a partir de 1973, en los comunicados y documentos que la disidencia publicó en la revista Militancia Peronista para la Liberación, muchos de ellos bajo el título de "Cartilla para militantes". Desde 1974 en adelante, y retomando una tradición que se venía expandiendo en distintos ámbitos militantes del país, los "sabinos" editaron una revista propia, con el nombre Puro Pueblo (que, a partir del número 4, se llamó Puro Pueblo Venceremos, por un requisito de propiedad intelectual). La publicación, dirigida desde Córdoba por Luis Rodeiro (escritor de los artículos de Nuevo Hombre así como del "Documento Verde"), tuvo 6 números (desde julio a septiembre de 1974), con una tirada quincenal que rondaba los 20.000 ejemplares, y con distribución en Córdoba, Santa Fe, Buenos Aires y Tucumán, a través de envíos a organizaciones de base y también por la venta en quioscos de diarios. La revista contó con un grupo de apoyo en Buenos Aires, hasta que se interrumpió, en un clima hostil de cierre de distintos proyectos editoriales y de creciente cercenamiento de las libertades públicas. Es de remarcar que, a diferencia del resto de las comunicaciones, esta publicación no explicitó el vínculo con la disidencia: los argumentos y símbolos circularon como un discurso alternativo a otros grupos que adscribían al peronismo y a la revolución, sin mención de la pertenencia de sus enunciadores. Podría decirse que a partir de la revista la Columna aspiraba a mimetizarse con el sujeto a representar, "puro pueblo".

Ahora bien, a pesar de las modificaciones, a lo largo de los meses las críticas hacia Montoneros que la disidencia buscó comunicar fueron bastante similares, aunque no exentas de tensiones. Por ejemplo:

El peligro no ausente en las organizaciones revolucionarias peronistas sería no haber superado la tendencia aparatista o militarista que es casi natural en todo proceso de formación y que se traduce en el fondo - aun inconscientemente- por un cierto desdén por lo político y que obstaculiza el entendimiento claro del momento situacional. Desdén por lo político y confianza excluyente en lo militar que lleva a la tendencia a idealizar la clase o el Movimiento. ${ }^{10}$

\footnotetext{
${ }^{8}$ El acto inaugural del Peronismo Descamisado fue el 22 de diciembre de 1973 en el local del Club YPF de la ciudad de Córdoba. Véase Militancia, 31, 17/01/74, 30-33.

${ }^{9}$ Nuevo Hombre, 23, 22/12/1971, 4-5 у 24, 29/12/1971, 4-5 у 11.

${ }^{10}$ Nuevo Hombre, "El peronismo hoy", 24, 29/12/1971, 4.
} 
Había un análisis simplista, genérico y espontaneísta del peronismo, que, si bien se asentaba sobre innegables verdades históricas, no calaba ni se percataba de la profunda contradicción que se daba en su seno. (....) La "idealización", la ideologización de la lucha armada, nos convencía que bastaba el mero voluntarismo de un pequeño grupo de iniciados, mientras dejábamos a la clase trabajadora en su dispersa multitud, en su inorgánica conexión, en manos de las direcciones reformistas y claudicantes. ${ }^{11}$

No comprendemos ni compartimos la decisión de la organización Montoneros [en relación a la declaración de pase a la clandestinidad]. Por el contrario -como peronistas y revolucionarios- la lamentamos. No dan un salto cualitativo, fruto del proceso de masas, sino que vuelven a una etapa pasada. Nosotros creemos que estamos ante una etapa predominantemente política. ${ }^{12}$

Los cuestionamientos se dirigían, en primer lugar, a la interacción de Montoneros con otros actores del peronismo (por ejemplo, a las negociaciones en vistas de la apertura electoral de 1972 y el armado del Frente Justicialista de Liberación -FREJULI-). Según los sabinos, buena parte de la dirigencia sindical y política del peronismo era "traidora" y "oportunista". De allí que, en el marco del clivaje entre posturas "movimientistas" y "alternativistas" que recorría algunas redes peronistas de ese entonces, ${ }^{13}$ no consideraban al peronismo como un fenómeno "revolucionario" en su conjunto, sino heterogéneo. De modo que tendían a criticar de "reformista" e "integracionista" toda interacción con otros sectores del Movimiento. Esta lectura se mantuvo, incluso, en tiempos del enfrentamiento de Montoneros con Perón y con la Confederación General del Trabajo (CGT) en 1973 y 1974. Y se asociaba, además, al carácter problemático que, según la disidencia, tenían las instituciones liberal-democráticas para el peronismo. En este sentido, si bien apoyaron las candidaturas del FREJULI tanto en marzo como en septiembre de 1973, no asistieron a las distintas reuniones que Perón realizó con los sectores juveniles. Buscaron despegar actividades sin circunscribirse a su liderazgo. En segundo lugar, la disidencia afirmaba que la organización sobrevaloraba la violencia, mistificaba y heroificaba la militancia armada, y desestimaba el trabajo de base. La acusaban de querer sustituir al pueblo, situándose en el "centro de gravedad" de la revolución. En continuación con ello, se denunciaba su carácter "foquista" y "militarista", contradiciendo, si se quiere, la impugnación anterior ligada al "movimientismo", puesto que, por definición, el esquema y la teoría del foco no se llevan bien con las alianzas políticas "movimientistas". No obstante, los documentos sabinos lo resolvían aseverando que Montoneros era foquista y que su "movimientismo" era oportunista. Como corolario de esta crítica, los disidentes argumentaban que las armas sólo debían ser aceptadas siempre y cuando se conjugaran con una militancia de "superficie".

11 "Documento Verde", Lucha Armada en la Argentina, 6, Buenos Aires, 2006, Anexo, 7.

12 Puro Pueblo, 5, 1 quincena de septiembre de 1974, 3.

13 Mientras que para el "movimientismo" el peronismo resultaba relativamente homogéneo, para el "alternativismo" las diferencias en su interior eran insalvables y se vinculaban a una desigualdad de clase. Además, para esta última postura, era necesario trabajar por fuera de las estructuras tradicionales del Movimiento. Véase Lanusse, op. cit. 
Es de notar que esta crítica al militarismo montonero matiza el diagnóstico que todavía hoy circula sobre el supuesto desvío hacia el militarismo y la violencia que habría atravesado a la organización a mediados de los años setenta, sustituyendo los ideales y valores políticos precedentes. ${ }^{14}$ Como lo patentan los argumentos de esta temprana disidencia, el militarismo fue parte de las prácticas y símbolos de los comienzos. De hecho, los propios documentos montoneros habían exhibido esta apelación a gramáticas y estrategias bélicas. ${ }^{15}$ De modo que, aunque exceda los objetivos de estas páginas, podría afirmarse que los cuestionamientos de esta disidencia obligan a precisar mejor el tipo de transformaciones que protagonizó la organización desde mediados de la década, que escapan al esquema de un desvío, de una modificación radical, o de una "traición" con respecto a los principios originarios.

Ahora bien, por su parte, la Conducción Nacional buscó invisibilizar la sucesión de hechos que acompañaron esta ruptura. Se negó a difundir y discutir las primeras críticas emitidas desde la cárcel. Al tiempo, hizo circular el rumor de que los presos desconocían el valor de la lucha armada y debían "estudiar el pensamiento nacional". ${ }^{16}$ Como respuesta disciplinaria, expulsó a varios militantes de distintas regionales que recibieron con simpatía el "Documento Verde". ${ }^{17}$ Finalmente, nunca debatió los planteos de la Columna una vez constituida. Por tanto, el mecanismo de gestión de las diferencias surgidas al interior de la militancia consistió en ignorarlas, quitarles estatus o entidad. Entre la vasta y cuantiosa prensa montonera, sólo aparece mención en un número de la revista El Peronista lucha por la Liberación, que siguió a El Descamisado, en el marco de una impugnación a varias disidencias:

Ajenos a la necesidad de construir la unidad del pueblo, la provocación de la ultraizquierda infantilista, da cabida desde 'Militancia' a todos los sectores (Sabino, Artigas, Coocke-Pujadas [sic], 1 Mayo), promocionándolos como supuestas columnas montoneras (...) Su falta real de espacio político, su falta de proyecto, los hace hacer, objetivamente una práctica contrarrevolucionaria para poder existir. ${ }^{18}$

Lo cierto es que, en tensión con estas declaraciones, la primera disidencia de Montoneros había establecido distintos dispositivos comunicativos para hacer circular sentidos específicos sobre la coyuntura y el proyecto revolucionario. Comunicados, documentos y prensa fueron parte de la conformación de esta ruptura. Su desarticulación ocurrió en 1975, poco después de la realización de un primer y último congreso, en el

\footnotetext{
14 Véase Richard Gillespie, Soldados de Perón. Los Montoneros, Buenos Aires, Grijalbo, 1987; Pilar Calveiro, Política y/o violencia. Una aproximación a la guerrilla de los años 70, Buenos Aires, Norma, 2005.

${ }^{15}$ Véase "Línea Político-militar", 1971, Roberto Baschetti (comp.), Documentos 1970-1973. De la guerrilla peronista al gobierno popular, La Plata, De La Campana, 2004, 249-270.

${ }^{16}$ Rodeiro, op.cit., 1996, 96-97.

${ }^{17}$ Seminara, op. cit., 43-45.

18 “Los provocadores", El peronista, 5, 21/05/74, 6.
} 
marco de un salto considerable de la trama represiva legal e ilegal que venía dándose desde tiempo atrás. ${ }^{19}$

\section{La Juventud Peronista Lealtad}

La Juventud Peronista Lealtad fue más inorgánica que la Columna Sabino Navarro. Si bien algunas de sus redes tuvieron articulación, otras se desprendieron sin mucha coordinación. Una instancia clave fue un congreso regional realizado en febrero de 1974 en la localidad bonaerense de Baradero por miembros de la Columna Oeste que desde hacía meses venían en conflicto con las directivas e intervenciones de sus superiores. La reunión concluyó con una declaración crítica a la Conducción Nacional que se entregó a Perón, y el intento de algunos militantes por recorrer ciudades de Buenos Aires y de otras provincias para lograr adhesiones. A su vez, otras columnas, unidades básicas e integrantes del circuito armado y de la llamada Tendencia Revolucionaria (de las Juventudes Peronistas Regionales, de la Juventud Trabajadora Peronista, de la Juventud Universitaria Peronista, de la Unión de Estudiantes Secundarios, del Movimiento Villero Peronista) estaban rompiendo con la cúpula montonera. Los desprendimientos ocurrieron hasta aproximadamente mediados de $1974 .^{20}$

Para ese entonces, Montoneros se había convertido en una gran organización político-militar, con redes a lo largo del país en universidades, colegios, barrios, fábricas, y villas. Ello había ocurrido en paralelo al crecimiento de las rispideces con Perón. Aunque éstas databan del comienzo del vínculo, ${ }^{21}$ desde el regreso de aquél de su exilio, la situación empeoró. Dos días después del triunfo electoral que lo llevó por tercera vez a la presidencia, Montoneros asesinó, sin reconocerlo salvo en su revista clandestina Evita Montonera, ${ }^{22}$ a José Ignacio Rucci, secretario general de la CGT y pieza fundamental en el armado político del líder del Movimiento. Por su parte, éste venía endureciendo las declaraciones hacia la organización, en el marco de una progresión de la trama represiva legal e ilegal del país. ${ }^{23}$

En este contexto, se formalizaron los Montoneros Soldados de Perón, la Juventud Peronista Lealtad, la Unión de Estudiantes Secundarios Lealtad, la Juventud Universitaria Lealtad, y la Juventud Trabajadora Peronista Lealtad, con redes en la Capital Federal y provincia de Buenos Aires, en Santa Fe, en Corrientes, en Neuquén y en algunas localidades del sur del país. Así, la disidencia reprodujo el esquema de su espacio de origen, que conjugaba actividades de superficie y clandestinas. Mantuvo el circuito armado, aunque a pedido de Perón efectuó una "voladura" simbólica de algunas armas en la zona del Delta para expresar el abandono de la política militarista. Entre sus dirigentes, estaban Eduardo Moreno, Alejandro Peyrou, Enrique Padilla, Nicolás Giménez, Norberto Ivancich,

\footnotetext{
${ }_{19}$ Marina Franco, Un enemigo para la Nación. Orden interno, violencia y subversión, 1973-1976, Buenos Aires, Fondo de Cultura Económica, 2012.

${ }^{20}$ Salcedo, op. cit; Pozzoni, op. cit.; Duzdevich, op. cit.

${ }^{21}$ Beatriz Sarlo, La pasión y la excepción. Eva, Borges y el asesinato de Aramburu, Buenos Aires, Siglo XXI, 2003, 134-200.

22 “Justicia popular", Evita Montonera, 5, junio-julio 1975, 18.

${ }^{23}$ Marina Franco, op. cit.
} 
Ernesto Villanueva, Jorge Obeid, Patricio Jeanmaire, los sacerdotes Jorge Galli y Jorge Goñi. Algunos se reunieron con Perón, informal y/o formalmente en las reuniones que para ese entonces realizaba con los sectores juveniles. Entre las actividades más relevantes, se cuentan un congreso en abril de 1974, en la Facultad de Ciencias Económicas de la Universidad de Buenos Aires; otro en la Unión Ferroviaria de Santa Fe en el mes de mayo; y un último en la Federación de Obreros y Empleados Telefónicos de la República Argentina en la segunda mitad del año. Además, existió una Coordinadora Provisoria de la JP Lealtad integrada por Horacio González, Edmundo González, José R. Canalls, Ricardo Gómez, Mario Maidovani, Norberto Ivancich, Mario Cisneros, Enrique H. Vallejos, Roberto Hyon y Víctor Espinosa. A ello habría que sumar cierta representación parlamentaria por parte de los diputados nacionales de la Juventud Peronista que no renunciaron a sus bancas luego del ríspido encuentro con Perón a raíz de la reforma del Código Penal el 22 de enero de 1974. Según cálculos de la propia disidencia, unos 5.000 militantes habrían concurrido el 1 de mayo a la Plaza a escuchar a su líder. ${ }^{24}$

Ahora bien, a pesar de su relativa inorganicidad, esta disidencia desplegó varias comunicaciones. Una primer intervención circuló hacia fines de 1973 en parte de la Columna Oeste, en la localidad de Moreno, y fue una respuesta a la "Charla de la Conducción Nacional ante las agrupaciones de los frentes", documento que por esa época se "bajó" a la militancia discutiendo el panorama nacional y las estrategias a futuro, y distanciándose del proyecto de Perón. ${ }^{25}$ No obstante, si bien el escrito de Moreno presentaba varios cuestionamientos a la Conducción Nacional, no formalizaba la ruptura y tenía el tinte de una autocrítica. Tras el silencio ante los planteos, aquélla se volvió explícita en la declaración con la que se cerró el congreso de Baradero. Lo mismo ocurrió en la solicitada firmada por "Montoneros Soldados de Perón" que se publicó el 15 de marzo de 1974 en el diario La Razón. Entre principios y mediados de 1974, apareció el folleto "Esta es nuestra historia", que situaba a la Lealtad en la larga historia del peronismo. Otros documentos, declaraciones y comunicados de distintos sectores de la militancia aparecieron, en muchos casos sin coordinación entre sí, manifestando las rupturas y el desconocimiento de la Conducción Nacional. Finalmente, habría que mencionar Movimiento para la Reconstrucción y Liberación Nacional. Aunque no fue una revista oficial de la disidencia, buscó difundir los debates que la atravesaban. Bajo la dirección de Miguel Saiegh, editó 11 números desde abril a septiembre de 1974, con una tirada quincenal de unos 7.000 a 8.000 ejemplares que se vendían en quioscos de diarios o se distribuían de manera gratuita, fundamentalmente en Capital Federal y Gran Buenos Aires. $^{26}$

La lectura de todas estas intervenciones permite vislumbrar que la enunciación de la ruptura y del enfrentamiento con la organización de procedencia fue distinta a la de los sabinos:

\footnotetext{
${ }^{24}$ Salcedo, op. cit.; Movimiento, 1, 1 quincena de mayo de 1974, 27; Movimiento, 2,2 quincena de mayo de 1974, 28; Aiscurri, op. cit., 168-169; Montero, op. cit.; Duzdevich, op. cit.

25 Roberto Baschetti (comp.), Documentos 1973-1976. De Cámpora a la ruptura, v.1, La Plata, De la Campana, 1996, pp. 258-311.

${ }^{26}$ Salcedo, op. cit., 299-317; Duzdevich, op. cit.; 206-207; Pozzoni, op. cit.; testimonios que me brindaron ex militantes, 02/06/2011, 15/07/11, 19/04/2012, 19/05/2011, 29/08/2011.
} 
Las desastrosas propuestas políticas que se manejaron en JP luego de la subida de Cámpora al gobierno se debieron, en gran parte, a que todo el proceso se analizó y evaluó desde cuerpos doctrinarios ajenos al justicialismo, particularmente el marxismoleninismo. ${ }^{27}$

El equívoco de nuestra conducción de JP, en esta emergencia, ha sido claro: se confundieron los tiempos de su poder movilizador. Una cosa fue movilizar con las banderas del peronismo, leal a Perón y su conducción, y otra (muy distinta) darse un proyecto propio y pretender una misma respuesta movilizadora, al margen del proyecto estratégico de Perón. ${ }^{28}$

La conducción nacional de la Organización fue abandonando paulatinamente los objetivos que dieron sentido a Montoneros y asumiendo una concepción ideológica que nos llevó a la incomprensión y al enfrentamiento del proyecto fijado por el Conductor del pueblo argentino. Ese enfrentamiento tiene su más evidente expresión en una actitud que lleva a tomar como irreconciliables las diferencias internas existentes en nuestro Movimiento, que en cambio podrían superarse en un marco de unidad y organización. (...) En suma, esa política antepone el esquema de un socialismo dogmático a la experiencia, la voluntad y la conciencia del pueblo peronista. ${ }^{29}$

Este sector [las Juventudes Peronistas Regionales] padeció una deformación gradual que comenzó cuando quisieron adueñarse de prácticamente todos los méritos de la lucha contra la dictadura, que compartieron con otros varios sectores [...]. Como 'autores' de la lucha se consideraron propietarios del periodo que venía después y procuraron utilizar las estructuras del peronismo para convertirse en eje del nuevo poder. Las deformaciones fueron en aumento: por un lado, un matonismo nacido del uso constante de los fierros y del convencimiento -erróneo- de que el manejo de las armas, en las dosis homeopáticas del terrorismo urbano, puede ser el camino al poder; por el otro, la omnipotencia de creer que bastanban sus consignas para 'apoderarse' del peronismo disputando a Perón la conducción del proceso y planteando un proyecto alternativo. ${ }^{30}$

Según los "leales", la Conducción Nacional de Montoneros venía cometiendo varios errores desde la llegada de Perón al país en junio de 1973. El primero era enfrentarse a su liderazgo, intentando reemplazarlo en la conducción del peronismo. La revista Movimiento fue bastante insistente en este punto, argumentando que la Conducción Nacional pretendía replicar los gestos de Augusto Timoteo Vandor durante la década anterior y defender un "peronismo sin Perón". Siguiendo con esta línea, la disidencia acusaba a la cúpula montonera de extremar las diferencias entre los sectores internos del Movimiento Peronista. Es decir, al contrario de la crítica de los sabinos, aquí se demandaba más "movimientismo" y vínculos con el resto de los actores de la galaxia peronista. El segundo equívoco que se le atribuía a la Conducción era que buscaba sustituir al pueblo. Al respecto, los disidentes

\footnotetext{
${ }^{27}$ Documento en respuesta a la "Charla...", Salcedo, op. cit., 308-309.

${ }^{28}$ Documento escrito a término de la reunión de Baradero, Duzdevich, op. cit., 206.

${ }^{29}$ Solicitada de Montoneros Soldados de Perón, La Razón, 15 de marzo de 1974.

${ }^{30}$ Movimiento, 6, 2 quincena de julio de 1974, 6.
} 
sostenían que debía disociarse la voluntad de los sectores populares de las acciones de la cúpula montonera, que no representaba más que a un grupo reducido de militantes. El tercer error refería al uso de las armas, que a juicio de los leales debían haberse abandonado con la apertura electoral. En lugar de ello, la Conducción Nacional habría pecado de "matonismo" y "fierrerismo", lo que contribuía a la inestabilidad del país. Nótese que esta crítica no impugnaba de manera radical la presencia de la violencia en los asuntos políticos sino que, en todo caso, la supeditaba a las condiciones particulares de gobierno. Esto es acorde, si se quiere, con el mantenimiento del circuito militar en la disidencia. Y rememora, además, la crítica de los sabinos al exceso de violencia armada.

Para los leales, todos estos errores - condensados en el asesinato de Rucci- se asentaban en una desviación ideológica hacia el marxismo-leninismo y en el abandono de los postulados peronistas, producto de la fusión de la organización con las Fuerzas Armadas Revolucionarias (FAR) formalizada en octubre de 1973. Este diagnóstico replicaba una discusión sucedida años atrás en las Fuerzas Armadas Peronistas (FAP), entre "oscuros" e "iluminados", representantes de la postura "movimientista" y la "alternativa independiente", respectivamente. En ese entonces, los "movimientistas" se habían apartado de las FAP para integrarse a Montoneros. ${ }^{31}$ Con argumentos similares, algunos de ellos se trasladaban ahora a la Lealtad. De todas formas, es preciso aclarar que la revisión de los documentos anteriores de Montoneros tensiona este argumento. En ellos se aprecia un uso corriente de conceptos como "foco", "vanguardia" y "ejército" así como recurrentes interpretaciones de la coyuntura en términos clasistas. ${ }^{32}$ De modo que, en verdad, no había demasiada novedad ideológica en la llegada de las FAR. Las propias impugnaciones de los sabinos de 1972 contra el uso de las armas habían dado cuenta de ello. En todo caso, es innegable que el diagnóstico de la desviación ideológica jugó como un mito fundante de esta disidencia.

Ahora bien, si el enfrentamiento de esta disidencia fue más radical que el de los sabinos, también lo fue la reacción de la Conducción Nacional, que excedió las expulsiones y alguna desestimación en la prensa, ${ }^{33}$ y se entramó con los cambios de la estructura de la organización y del panorama nacional. Ya estaban vigentes las "Disposiciones sobre la justicia revolucionaria", un código disciplinario que, si bien no había sido leído por todos los militantes, era parte de la cultura montonera y trascendía las penas efectivamente aplicadas. Las Disposiciones sancionaban con "fusilamiento" la "deserción en combate" y la "traición" (entendida sin demasiada precisión como "servir conscientemente al enemigo"), aunque no la "deserción de la Organización" que no tenía prevista pena explícita. Es de destacar que en la normativa se evocaba la "autocrítica", tan conocida en el mundo de las izquierdas, según la cual el imputado debe juzgar su conducta, mostrar arrepentimiento y reconocer los mandatos superiores como propios. Es decir, un dispositivo

31 Eduardo L. Duhalde y Eduardo M. Pérez, De Taco Ralo a la alternativa independiente. Historia documental de las Fuerzas Armadas Peronistas y del Peronismo de Base, La Plata, Ediciones De La Campana, 2003.

${ }^{32}$ Basta con ver la "Línea Político-Militar", Baschetti, op. cit, y el Boletín N 1, segunda quincena de mayo de 1973, citado Roberto Baschetti (comp.), Documentos 1970-1973. De la guerrilla peronista al gobierno popular, La Plata, De La Campana, 1995, 593.

33 "Los logreros", El Peronista, 5, 21/05/74, 8. 
que se orientaba a ocluir toda distancia y diferencia respecto de las prescripciones oficiales.

Según los testimonios, al producirse la ruptura de la Lealtad, la organización escribió un documento titulado "Tratamiento a los disidentes", previendo sanciones que incluían la muerte. Lo cierto es que no se conocen asesinatos de leales bajo imputación de disidencia, pero sí numerosas amenazas de "ajusticiamiento" acompañadas con acusaciones de "traición". También encierros en "carceles del pueblo" con la exigencia de realizar autocríticas, o "traslados" a otros lugares del país. Tales son los casos de Dante Oberlin en 1973 o de Virginia Maratea a principios de 1974, a quien además le hicieron un juicio por haberse quedado con armas de la organización antes de trasladarla a la provincia de San Juan. A su vez, otro testimonio aduce que la organización habría quemado una unidad básica de la Lealtad. Finalmente, se dieron varias situaciones conflictivas a raíz de la exigencia a los disidentes de entregar las armas y los vehículos "recuperados".34

En suma, la Lealtad se construyó en paralelo a la resistencia montonera a las discusiones y las divergencias, desplegando varios dispositivos para comunicar sus prácticas, decisiones y concepciones. Con todo, el espacio disidente no persistió mucho más allá de 1974. Las razones fueron varias: al clima de represión creciente habría que agregar el carácter desarticulado y descentralizado de la experiencia, que buscaba diferenciarse de la rigidez y las jerarquías montoneras, y que no permitía tomar demasiadas decisiones. Asimismo, surgieron diferencias en relación al gobierno de María Estela Martínez de Perón, una vez fallecido Perón en julio de 1974. En este marco, se diluyó la última disidencia que Montoneros tuvo antes del exilio de su Conducción.

\section{El Peronismo Montonero Auténtico}

Esta disidencia surgió en 1979, en el exilio y con buena parte de la militancia montonera asesinada o detenida-desaparecida por el terrorismo estatal. Para ese entonces, la Conducción Nacional, que había convertido la otrora "organización político-militar" en el "Partido Montonero", el "Ejército Montonero" y el "Movimiento Peronista Montonero", evaluaba que era el momento desplegar una iniciativa armada de envergadura. Afirmó que era hora de finalizar la etapa de la "Resistencia" dentro de la "Defensiva Estratégica", que la dictadura argentina se encontraba en crisis, y que las movilizaciones sindicales iban en aumento. A partir de este diagnóstico, lanzó "la Contraofensiva con la seguridad del éxito". 35

\footnotetext{
34 Lenci, op. cit; Duzdevich, op. cit., 225 y 229; Salcedo, op. cit., 25; testimonios ya citados. Las Disposiciones se encuentran en la Comisión Provincial por la Memoria situada en La Plata, Buenos Aires: Archivo DIPBA, Mesa D (s), Carpeta Varios, Legajo No581, 16 folios. Según los artículos 39) y 40), entraban en vigencia a partir del $1^{\circ}$ de enero de 1973, pero con posibilidad de aplicarse retroactivamente si el acusado lo aceptaba. De acuerdo al memorando de la SIPBA, fueron secuestradas en Mendoza por la policía local el 24/10/1972. Debo aclarar que aunque la sanción y aplicación de esta normativa fue paralela al proceso de creación y consolidación de los sabinos, considero que su relevancia es mayor en el caso de los leales, puesto que ya llevaba varios meses en el horizonte de sentido de las prácticas militantes.

35 Boletín Interno $\mathrm{N}^{\circ} 12$, "Balance de la campaña Carlos Hobert de lanzamiento de la Contraofensiva popular", 1980, y nota "Organizarse para vencer", Evita Montonera, 23, enero de 1979, 9. Véase también Marcelo Larraquy, Fuimos Soldados. Historia secreta de la contraofensiva montonera, Buenos Aires,
} 
En este marco se sucedió una nueva ruptura. En verdad, su comprensión requiere volver a la historia de la Columna Norte de Montoneros durante 1975 y los primeros meses del Proceso de Reorganización Nacional. En dicho periodo, se habían acumulado innumerables conflictos entre los militantes locales y la Conducción Nacional. Las críticas se anidaban en las dificultades para el trabajo fabril y territorial, dada la decisión de autoclandestinización de la organización de septiembre de 1974. A ello se sumaban las quejas por la falta de apoyo logístico y financiero a la militancia, en un panorama de creciente y cruenta represión estatal y paraestatal. A pesar de lo que suele afirmarse en la contada literatura sobre el tema, las tensiones excedían los "desplantes" de Rodolfo Galimberti, "El Loco", y estaban lejos de circunscribirse a un conflicto entre un sector militarista, "las tres M" (los "Montoneros Más Malos"), y la cúpula montonera. ${ }^{36}$ Antes bien, incluían a más dirigentes (como Francisco "Pancho" Rivas o Marcelo "Francisco" Ravé) y a otras redes vinculadas al trabajo de "superficie" en el territorio. Los militantes de Norte demandaron durante un tiempo la realización de un congreso nacional para discutir la composición de la cúpula montonera y establecer mayores espacios para la toma de decisiones, pero en respuesta se ideó un dispositivo que mantuvo el status quo: hacia mediados de 1976 se realizó una votación entre los cuadros con grado de oficial en adelante, que ratificó a la Conducción Nacional e impugnó a los militantes de Norte, quienes fueron degradados. ${ }^{37}$

En verdad, la Conducción Nacional desplegó varios dispositivos disciplinarios, como la intervención sucesiva de la Columna (debido a que muchos de los interventores se plegaban a las demandas locales), los traslados, las despromociones, y la restricción y/o el bloqueo de recursos (dinero, documentos y armas). Para ese entonces, se había sancionado una nueva normativa disciplinaria, el "Código de Justicia Penal Revolucionario", aprobado en octubre de 1975 en una reunión del Consejo Nacional de Montoneros. La flamante reglamentación repetía delitos del viejo código y tipificaba más. Por ejemplo, la "traición" definida como "colabor[ar] o serv[ir] concientemente al enemigo", la "deserción de la organización" sin la aprobación de los superiores, la "insubordinación" que suponía incumplir las "órdenes o resoluciones emanadas de [los] responsables", o la "conspiración" entendida como "una actividad concreta orientada a lograr una división o un fraccionamiento de la organización". Aunque, según los testimonios referidos a esta etapa, no se conocen casos de asesinatos a disidentes o críticos, lo cierto es que la normativa

Aguilar, 2006; Hernán Confino, "Tensiones de un retorno: La Contraofensiva Estratégica Montonera de 1979 y 1980 en Argentina”, Izquierdas, 28, Santiago de Chile, 2016, 274-291.

${ }^{36}$ Roberto Caballero y Marcelo Larraquy, Galimberti: de Perón a Susana, de Montoneros a la CIA, Buenos Aires, Norma, 2000.

${ }^{37}$ La información sobre la Columna Norte es escasa. Pueden verse Roberto Caballero y Marcelo Larraquy, op. cit., 293-337; Larraquy, op. cit., 135-138; Marisa Sadi, El caso Lanuscou. Columna Norte, la otra historia, Buenos Aires, Nuevos Tiempos, 2009; Luciana Mingrone, "Pelearle a María. Disidencias en Montoneros (1972-1976)", ponencia del II Segundo Congreso de Estudios sobre el Peronismo, Tres de Febrero, 2010; Federico Lorenz, Algo parecido a la felicidad, Una historia de la lucha de la clase trabajadora durante la década del setenta (1973-1978), Buenos Aires, Edhasa, 2013; Fernanda Nicolini y Alicia Beltrami, Los Oesterheld, Buenos Aires, Sudamericana, 2016. Para la breve descripción realizada, incluí el testimonio que me brindaron dos ex integrantes de la Columna Norte y de la disidencia, 27/09/2016 y $13 / 10 / 2016$. 
advertía qué prácticas podían castigarse, articulando un horizonte de sentido y una cultura política particulares. ${ }^{38}$

De todos modos, amén de la intensidad del conflicto, en Norte no se concretó una ruptura. Incluso, varios de los que lograron sobrevivir y exiliarse volvieron a vincularse con la dirección montonera. Luego de realizar, en algunos casos, "autocríticas", se incorporaron a la Juventud del Movimiento Peronista Montonero y/o al Ejército Montonero. De estas redes surgió la nueva disidencia, a la que se sumaron exiliados disconformes con la Conducción Nacional y su diagnóstico sobre la coyuntura argentina. El entonces secretario general de la Juventud del Movimiento Peronista Montonero, Rodolfo Galimberti, la encabezó, después de entrenar militantes en México para el retorno a la Argentina como miembros del "Comando Táctico Adelantado" (que, según los planes montoneros, debía anteceder a las "Tropas Especiales de Agitación" y las "Tropas Especiales de Infantería", pilares de la Contraofensiva). Entre otros, lo acompañaron Juan Gelman, Pablo y Miguel Fernández Long, Patricia y Julieta Bullrich, Marcelo Langieri, Arnaldo Lizaso, Héctor Mauriño, Raúl Magario, Victoria Vaccaro, Claudia Genoud y Silvia Di Fiorio.

El 29 de mayo de 1979 la disidencia presentó su "mesa promotora" en París. Con parte del dinero del Partido Montonero, "recuperado" bajo el argumento de que provenía del secuestro de Juan y Jorge Born de septiembre de 1974 protagonizado por la Secretaría Militar de Norte, se realizaron algunas actividades. Entre otras, operativos de retorno a la Argentina para contactar los poquísimos militantes de "base" aislados en el territorio, distribuir documentos, realizar propaganda, y trazar redes para la disidencia. A su vez, se efectuó un congreso en Estocolmo, unificando los distintos militantes que circulaban por Europa. Podrían mencionarse, por último, los vínculos entablados con el Instituto CLADER, un centro de formación intelectual europeo presidido por Héctor Gambarotta. ${ }^{39}$

Ahora bien, aquí también, a través de distintos documentos y publicaciones, se comunicaron largamente las razones de la ruptura. Para empezar, el 25 de febrero de 1979, en el periódico francés Le Monde apareció una carta firmada por Galimberti y Gelman que formalizaba la disidencia. Unos días después, el 12 de marzo, Gelman escribió una carta a Rodolfo Puiggrós, integrante del Movimiento Peronista Montonero, explicándole su enfrentamiento con la Conducción Nacional. En junio de 1979, se dio a conocer un documento más extenso, "Reflexiones para la construcción de una alternativa peronista montonera auténtica", apodado "La albóndiga". Algunos de los militantes que regresaron al país, imprimieron en mimeógrafo y distribuyeron artesanalmente los primeros números de la revista Jotapé, que contaba, entre otras, con las firmas de Galimberti y de "Carolina Serrano" (Patricia Bullrich). Por otra parte, la disidencia hizo circular de manera clandestina, fuera y dentro del país, los documentos críticos que Rodolfo Walsh había escrito en 1976 y 1977, y que sus superiores habían ignorado, aun habiendo reivindicado su

\footnotetext{
38 “Código de Justicia Penal Revolucionario", Lucha Armada en la Argentina, 8, Buenos Aires, 2007, 124127. Según el artículo 52), el Código entró en vigencia el $1^{\circ}$ de enero de 1976, aunque también contemplaba "los hechos acaecidos durante el año 1975 cuando no haya oposición del acusado a esa aplicación retroactiva", ibid, 127.

39 Testimonios ya citados; Caballero y Larraquy, op. cit.
} 
"Carta de un escritor a la Junta militar". ${ }^{40}$ Los editaron en octubre de 1979 bajo el título "Los papeles de Walsh" y adujeron que con ellos buscaban romper "el silencio con que la OPM intentó cubrir [esa] manifestación de pensamiento crítico surgido en su seno". 41

Aunque suele afirmarse que la razón de la separación fue la Contraofensiva, las argumentaciones de la disidencia fueron más complejas:

El prolongado alejamiento de la Conducción Nacional del Partido del territorio argentino, $\mathrm{y}$ en consecuencia de las condiciones reales en las que se desarrolla la Resistencia, sumada a la falta de ejercicio efectivo de la conducción de las fuerzas que luchan en el país, ha agravado viejas desviaciones nunca corregidas del todo, a la vez que ha favorecido la aparición de nuevas deformaciones. (...) resurgimiento del militarismo de cuño foquista (...) la reafirmación de la concepción elitista del Partido de Cuadros, que ha generado un progresivo aislamiento de las masas y de sus organizaciones reivindicativas naturales (...) la definitiva burocratización de todos los niveles de conducción del Partido (...) la ausencia absoluta de democracia interna que yugula todos los intentos de reflexión crítica, calificándola de defección o de traición, enmascarando la falta de respuesta política con un triunfalismo irresponsable que no convence a nadie. ${ }^{42}$

Nosotros creemos que hay que comenzar por la recuperación del espacio del peronismo montonero objetivamente desgajado de la organización por el tacticismo oportunista que renunció inclusive a los principios que dieron origen al proyecto Montoneros (...) Estos errores de concepción podrían sintetizarse a los efectos de un primer análisis en tres cuestiones: la concepción antidemocrática, el sectarismo, y el militarismo (...) [La primera] hay que rastrearla en el origen estrictamente foquista de los primero núcleos que conformaron la OPM -que, resulta interesante destacar, se conservaron siempre en la cúspide de la pirámide organizativa- (...) El otro grave problema que se convirtió en un obstáculo insalvable para el desarrollo del trabajo político en las masas, fue el sectarismo, alentado como un mérito desde la conducción (...) Una cosa es clara: la conducción de la OPM mantiene una concepción de la organización de la violencia que se ha demostrado trágicamente ineficaz (...) Se puede hacer un 'foco' con diez, o intentar hacerlo con cien mil; lo primero se hizo antes del 72; lo segundo, se intentó después del 72 (...) El fracaso de esta 'conducción' se debió no sólo a que no tenía un proyecto, sino también a que demostró una impotencia absoluta para construir política y organizativamente en el espacio de representatividad que tenía la Tendencia. ${ }^{43}$

Si la vanguardia niega al movimiento, desconoce su propia historia y asienta las bases para cualquier desviación (...) Hasta el 24 de marzo del 76, planteábamos correctamente la lucha interna por la conducción del peronismo; después del 24-3-76, cuando las condiciones eran inmejorables para esa lucha, desistimos de ella y en vez de hacer política, de hablar con todo el mundo, en todos los niveles en nombre del peronismo, decidimos que las armas principales del enfrentamiento eran militares (...) La línea del

40 Mouvement Peroniste Montonero, «Lettre ouverte d'un écrivain à la Junte militaire d'Argentine", sin fecha. Caballero y Larraquy, ob. cit., 323-325.

${ }^{41}$ Documento "Los Papeles de Walsh", 8 de octubre de 1979, 1.

42 Documento "Galimberti-Gelman. Una carta polémica", 22 de febrero de 1979.

${ }^{43}$ Documento "Reflexiones para la construcción de una alternativa peronista montonera auténtica", 9 de junio de 1979. 
Partido y los documentos que la expresan en los últimos 18 meses revelan, a mi juicio, una fuerte influencia del pensamiento maoísta en el aspecto político y de la doctrina de Clausewitz en el aspecto militar. ${ }^{44}$

Una vez más, los disidentes impugnaron el "militarismo" y el "foquismo". Adujeron que la Conducción Nacional interpretaba la coyuntura en términos militares, que evadía el trabajo político de "superficie", y que, en lugar de organizar a las "masas", se aislaba de ellas y era sectaria. Al realizar estas críticas, retomaban argumentos de las disidencias precedentes, marcando una tensión: por un lado, se argüía que estos errores constituían un desvío respecto de los fundamentos originales del proyecto político montonero, en tono similar a las afirmaciones de la Juventud Peronista Lealtad respecto de la discontinuidad ideológica que habría acontecido hacia mediados de los setenta; por otro lado, reconocían que se trataba de características que habrían acompañado al núcleo dirigente desde los comienzos, más en sintonía con la problematización de los núcleos originales que había explicitado la Columna José Sabino Navarro desde su "Documento Verde". Ambas explicaciones convivían desarticuladamente en los documentos de la disidencia. Además, se señalaba la ausencia de discusión interna y la "burocratización" de todas las redes montoneras, que bloqueaban todo cuestionamiento a las órdenes y directivas. ${ }^{45}$ Finalmente, se observaba un ciego "triunfalismo", y la imposibilidad de reconocer situaciones adversas y de admitir la responsabilidad por los errores cometidos en los métodos como en la organización de los sectores populares. Nada de esto suponía negar la pertinencia de la violencia en las intervenciones públicas, pero sí advertían que debía ser acompañada por la "lucha de masas". Con estos argumentos, la disidencia marcaba un fuerte enfrentamiento con el núcleo dirigente de Montoneros, que trascendía por mucho el acuerdo o el desacuerdo en relación a la implementación de la Contraofensiva. Incluso, según los testimonios, los disidentes se referían a la Conducción con el mote de "stalinista". 46

Nacional

Sobre la base de la normativa disciplinaria, en marzo de 1979 la Conducción acusó a los disidentes de "deserción”, “insubordinación”, “conspiración” y "defraudación”, y solicitó "la aplicación del máximo rigor que corresponda a la imposición de las penas por los delitos de que son acusados, teniendo en cuenta el daño que los mismos provocan por la particular circunstancia en que son cometidos, en momentos en que el conjunto de las fuerzas se están reagrupando a los fines del desarrollo de los planes de la Contraofensiva". Desoyó los cuestionamientos a la dinámica, las decisiones y las prácticas montoneras, y concluyó que "ningún traidor ni desertor de nuevo cuño podrá impedir el triunfo político de

\footnotetext{
${ }^{44}$ Idem, 5, 6 y 23. Sobre la ANCLA, véase Israel Lotersztain y Sergio Bufano (comps.), Rodolfo Walsh y la agencia de noticias clandestinas: 1976-1977, Buenos Aires, Ejercitar la memoria editores, 2012.

${ }^{45} \mathrm{Al}$ respecto, agregaban que "la conducción de la OPM ha creado un método de enmascaramiento de sus errores y de camuflage (sic) para ocultar la represión que ejerce sobre cualquier manifestación de discrepancia, método que el folklore montonero bautizó como 'la milonga de los cambios de etapa'. 'Cambios de etapa' que de haber ocurrido todos los que la conducción decretó, nuestra revolución sería la revolución con más etapas en la historia de la revolución mundial". Documento "Reflexiones...", 17.

46 Testimonios ya citados.
} 
la nueva consigna de la etapa 'CONQUISTAR EL PODER SINDICAL ES VENCER'".47 La pena máxima no se cumplió pero, desde luego, condicionó el transitar de los disidentes durante un tiempo. Con el paso de los meses, y a pesar de las varias formas de comunicación desplegadas, las redes del Peronismo Montonero Auténtico fueron desarticulándose. Una parte se involucró en la política de la transición argentina. De hecho, a pesar de la radicalidad de las críticas, algunos disidentes volvieron a vincularse con la estructura residual de Montoneros. ${ }^{48}$

\section{Reflexiones finales}

En las páginas anteriores, busqué echar luz sobre algunos de los grupos disidentes que tuvo Montoneros, concentrándome en los modos con los cuales buscaron distinguirse de su "organización madre". Para ello, me concentré en sus formas de comunicación, asumiendo que se trata de instancias fundamentales para los espacios identitarios, y no el simple reflejo de otras realidades más decisivas. Como patenta el recorrido, las disidencias dedicaron tiempo y recursos a desplegar dispositivos de comunicación a lo largo de su derrotero. Ahora bien, aunque es una indagación que amerita mayor profundización, los documentos y publicaciones revisados permiten esbozar reflexiones generales sobre los procesos de constitución de las disidencias, sus argumentaciones y sus símbolos.

En primer lugar, es de notar que cada disidencia tuvo su especificidad y que es impreciso homologar las redes de Montoneros como si se tratara de un actor lineal o, incluso, evocar la figura de la "izquierda peronista". ${ }^{49}$ Antes bien, la densidad histórica obliga a delimitar las distancias entre espacios y circuitos, amén de que todos ellos reivindicaran el peronismo y la idea de revolución. En segundo lugar, a pesar de la singularidad, es indudable que existieron similitudes: todas las disidencias criticaron el "militarismo" y demandaron, a su modo, más trabajo "de superficie" en el territorio, en las fábricas o en las universidades; ninguna impugnó de lleno la violencia como práctica legítima a la hora de dirimir los asuntos públicos; todas cuestionaron la desatención o sanción de la cúpula jerárquica ante sus planteos; casi todas responsabilizaron a la Conducción Nacional por los equívocos, exculpando al resto de las redes militantes; y todas mantuvieron, aunque sea por algún tiempo, el nombre de Montoneros en sus identificaciones. Ello posibilita pensar varias cuestiones. Por un lado, que, como anticipé precedentemente, el proceso de encuadramiento militar de los militantes y de intensificación de las intervenciones armadas que se desplegó a mediados de los setenta supone más una continuidad con los esquemas originarios que su desviación, corrupción o “traición”. Dichos símbolos y formas de interpretar la coyuntura existieron desde el

\footnotetext{
47 Resolución Nro 045/79, "Sobre la deserción de cinco militantes del partido y cuadtro milicianos en el exterior", 10 de marzo de 1979, mayúsculas originales.

${ }^{48}$ Caballero y Larraquy, op. cit.

49 Sobre la "izquierda peronista", véase Germán Gil, La izquierda peronista (1955-1974), Buenos Aires, Centro Editor de América Latina, 1989, y Mariano Fraschini, El brazo izquierdo de Perón. Ideólogos y actores de la izquierda peronista (1955-1974), Buenos Aires, Álvarez Castillo Editor, 2008.
} 
principio, tal como lo evidencian las críticas de la Columna Sabino Navarro. Por otro lado, que este diagnóstico de la "desviación", que, como señalé, aparece en algunos textos que hoy circulan sobre la época, reproduce la gramática y las discusiones con las que algunos protagonistas (la disidencia de la Lealtad y el posterior Peronismo Montonero Auténtico) leyeron el derrotero montonero, hace ya más de cuarenta años. Las acusaciones en torno al "desvío militarista", el "desvío foquista" y "el olvido del trabajo de superficie" no son sino formas con que los actores involucrados interpretaron la experiencia y tomaron distancia de ella. Si se quiere, son sus mitos y relatos de origen. Esto debería convocar, me parece, a renovar los términos actuales de comprensión del fenómeno montonero. Asimismo, creo que las similitudes entre las disidencias invitan a interrogar la atribución de culpas a la Conducción Nacional, que repitieron los protagonistas de aquel entonces y que a veces atraviesa la bibliografía que circula actualmente así como la memoria política y social. ${ }^{50}$ Porque ella tiende a desdibujar cómo, más allá del innegable peso de la cúpula en las decisiones, se reprodujeron determinadas prácticas en distintas tramas del espacio. Sin esa reproducción, seguramente incómoda para muchos, las decisiones de la cúpula no habrían existido. Finalmente, el recorrido por las disidencias patenta que la imbricación entre violencia y política pone en juego tensiones que no resultan sencillas para los militantes, que la "lucha armada" fue más que una simple herramienta o un método de intervención en el espacio público, como a veces se afirma, ${ }^{51}$ y que implica un elemento de orden decisivo. Desde una sociología de las identidades políticas, puede observarse que la violencia era parte constitutiva del espacio de pertenencia. Aun con todas sus críticas, las disidencias no dejaron de sostenerla ni abandonaron, tampoco, la etiqueta "Montoneros" para nominar su espacio.

A la vez, considero que las páginas anteriores exhiben puntos de continuidad en las respuestas que el resto del espacio dio a las disidencias. Es decir, el repaso por los tres casos ilumina modos de gestión de las diferencias que aparecieron desde el principio hasta el final, más allá de su evidente endurecimiento. Como se vio, la dinámica se orientaba a negar los desacuerdos, a quitarles visibilidad, a interpretarlos como "traiciones" al proyecto común, a rechazar el debate y a castigar su aparición (así se formalizaba, incluso, en los códigos normativos sancionados en 1972 y 1975). De modo que creo que no sólo se pretendía cuestionar el desacuerdo -mecanismo probablemente recurrente en diversos ámbitos políticos- sino que se negaba el estatus de la divergencia como tal. En otras palabras, los mecanismos para abordar la pluralidad de los asuntos humanos fueron su represión, sanción y ocultamiento, antes que su puesta en valor y su aceptación como rasgo propio del mundo compartido. Montoneros reprodujo una estructura rígida que en lugar de trazar lazos comunes a través de la diversidad tendió a generar más tensiones y quiebres. Este fue un elemento constitutivo de su identidad, que la pregunta por las disidencias y sus formas de comunicación también contribuye a problematizar.

\footnotetext{
50 Un ejemplo es Eduardo Anguita y Martín Caparrós, La voluntad. Una historia de la militancia revolucionaria en la Argentina, Buenos Aires, Planeta, 2006.

${ }^{51}$ Así aparece en Lanusse, op. cit.
} 


\section{Bibliografía}

-Aboy Carlés, Gerardo, Las dos fronteras de la democracia argentina. La reformulación de las identidades políticas de Alfonsín a Menem, Rosario, Homo Sapiens, 2001.

-Aiscurri, Mario, ¿Que vivan los perejiles!, Buenos Aires, Catálogos, 2003.

-Amorín, José, Montoneros: la buena historia, Buenos Aires, Catálogos, 2006.

-Anguita, Eduardo y Martín Caparrós, La voluntad. Una historia de la militancia revolucionaria en la Argentina, Buenos Aires, Planeta, 2006.

-Caballero, Roberto y Marcelo Larraquy, Galimberti: de Perón a Susana, de Montoneros a la CIA, Buenos Aires, Norma, 2000.

-Calveiro, Pilar, Política y/o violencia. Una aproximación a la guerrilla de los años 70, Buenos Aires, Norma, 2005.

-Confino, Hernán, "Tensiones de un retorno: La Contraofensiva Estratégica Montonera de 1979 y 1980 en Argentina", Izquierdas, 28, Santiago de Chile, 2016, 274-291.

-Duhalde, Eduardo L. y Eduardo M. Pérez, De Taco Ralo a la alternativa independiente. Historia documental de las Fuerzas Armadas Peronistas y del Peronismo de Base, La Plata, Ediciones De La Campana, 2003.

-Duzdevich, Aldo, Norberto Raffoul y Rodolfo Beltramini, La Lealtad. Los Montoneros que se quedaron con Perón, Buenos Aires, Sudamericana, 2015.

-Franco, Marina, Un enemigo para la Nación. Orden interno, violencia y subversión, 1973-1976, Buenos Aires, Fondo de Cultura Económica, 2012-Gillespie, Richard, Soldados de Perón. Los Montoneros, Buenos Aires, Grijalbo, 1987.

-Fraschini, Mariano, El brazo izquierdo de Perón. Ideólogos y actores de la izquierda peronista (1955-1974), Buenos Aires, Álvarez Castillo Editor, 2008.

-Gil, Germán, La izquierda peronista (1955-1974), Buenos Aires, Centro Editor de América Latina, 1989.

-Inchauspe, Leandro y Ana Noguera, "La Columna José Sabino Navarro: un acercamiento a la militancia armada peronista en la córdoba de los '70 a través de fuentes orales", I Workshop Interuniversitario "Partidos políticos y elecciones en espacios regionales y provinciales", Resistencia, 2011.

Navarro y su desarrollo en la Córdoba de los '70”, Revista Estudios, 34, Córdoba, 2015, 29-49.

-Ivancich, Norberto y Mario Wainfeld, "El gobierno peronista 1973-1976: los Montoneros (tercera parte)" en Revista Unidos, 7/8, Buenos Aires, 1985.

-Lanusse, Lucas, Montoneros. El mito de sus 12 fundadores, Buenos Aires, Vergara, 2007.

-Larraquy, Marcelo, Fuimos Soldados. Historia secreta de la contraofensiva montonera, Buenos Aires, Aguilar, 2006.

-Lenci, Laura, "Justicia, política y violencia. Un análisis de los cuerpos normativos montoneros 1972-1975", ponencia presentada en las II Jornadas de "Partidos Armados en la Argentina de los Setenta", UNSAM, 2008.

-Lorenz, Federico, Algo parecido a la felicidad, Una historia de la lucha de la clase trabajadora durante la década del setenta (1973-1978), Buenos Aires, Edhasa, 2013.

-Mingrone, Luciana, "Pelearle a María. Disidencias en Montoneros (1972-1976)", ponencia del II Segundo Congreso de Estudios sobre el Peronismo, Tres de Febrero, 2010.

-Montero, Ana Soledad, "Héroes, ortodoxos, disidentes y traidores. Los avatares de la Juventud Peronista Lealtad (1973-1976)", Red interdisciplinaria de estudios sobre historia reciente, 2009, 1014.

-Nicolini, Fernanda y Alicia Beltrami, Los Oesterheld, Buenos Aires, Sudamericana, 2016. 
-Peyrou, Alejandro, "Lealtad", Lucha Armada en la Argentina, Anuario, Buenos Aires, 2010, 4463.

-Pozzoni, Mariana, “'Leales' y 'traidores': La experiencia de disidencia de la Juventud Peronista Lealtad (1973- 1974)", Nuevo Mundo Mundos Nuevos [En ligne], Questions du temps présent, mis en ligne le 03 juin 2013, consulté le 24 octobre 2017.

-Rodeiro, Luis, Fantasías de bandoneón (una disidencia montonera), Buenos Aires, Ediciones de la Cortada, 1996.

--------, “El 'Documento Verde': la primera crítica a Montoneros desde Montoneros", Lucha Armada en la Argentina, 6, Buenos Aires, 2006, 56-61.

-----------, Textos Viscerales, Buenos Aires, Caterva, 2015.

-Sadi, Marisa, El caso Lanuscou. Columna Norte, la otra historia, Buenos Aires, Nuevos Tiempos, 2009.

-Salcedo, Javier, Los montoneros del barrio, Buenos Aires, Eduntref, 2011.

-Sarlo, Beatriz, La pasión y la excepción. Eva, Borges y el asesinato de Aramburu, Buenos Aires, Siglo XXI, 2003, 134-200.

-Seminara, Luciana, Bajo la sombra del ombú. Montoneros Sabino Navarro, historia de una disidencia, Buenos Aires, Imago Mundi, 2015

-Slipak, Las revistas montoneras. Cómo la organización construyó su identidad a través de sus publicaciones, Buenos Aires, Siglo XXI, 2015.

\section{Documentos}

-Baschetti, Roberto (comp.), Documentos 1970-1973. De la guerrilla peronista al gobierno popular, La Plata, De La Campana, 1995.

la Campana, 1996. -, Documentos 1973-1976. De Cámpora a la ruptura, v.1, La Plata, De

popular, La Plata, De La Campana, 2004.

-Boletín Interno $\mathrm{N}^{\circ} 12$ del Partido Montonero, "Balance de la campaña Carlos Hobert de lanzamiento de la Contraofensiva popular", 1980, en la Bibliothèque de Documentation Internationale Contemporaine, Nanterre, Francia.

-“Código de Justicia Penal Revolucionario", Lucha Armada en la Argentina, 8, Buenos Aires, 2007, 124-127.

-"Disposiciones sobre la justicia revolucionaria", en la Comisión Provincial por la Memoria, Archivo de la Dirección de Inteligencia de la Policía de la Provincia de Buenos Aires, Mesa D (s), Carpeta Varios, Legajo No581, 16 folios.

-“Documento Verde”, Lucha Armada en la Argentina, 6, Buenos Aires, 2006, Anexo, 7.

-El peronista lucha por la Liberación, Centro de Documentación e Investigación de la Cultura de Izquierdas en Argentina, Buenos Aires.

-Evita Montonera, Centro de Documentación e Investigación de la Cultura de Izquierdas en Argentina, Buenos Aires.

-“Galimberti-Gelman. Una carta polémica", 22 de febrero de 1979, en Centro de Documentación e Investigación de la Cultura de Izquierdas en Argentina, Buenos Aires.

- "Lettre ouverte d'un écrivain à la Junte militaire d'Argentine", sin fecha, Mouvement Peroniste Montonero, Bibliothèque de Documentation Internationale Contemporaine, Nanterre, Francia.

-"Los Papeles de Walsh", 8 de octubre de 1979, en Centro de Documentación e Investigación de la Cultura de Izquierdas en Argentina, Buenos Aires. 
-Lotersztain, Israel y Sergio Bufano (comps.), Rodolfo Walsh y la agencia de noticias clandestinas: 1976-1977, Buenos Aires, Ejercitar la memoria editores, 2012

-Militancia Peronista para la Liberación, en Centro de Documentación e Investigación de la Cultura de Izquierdas en Argentina, Buenos Aires.

-Movimiento para la Reconstrucción y Liberación Nacional, www.ruinasdigitales.com.ar.

-Nuevo Hombre, en Centro de Documentación e Investigación de la Cultura de Izquierdas en Argentina, Buenos Aires.

-Puro Pueblo, en Centro de Documentación e Investigación de la Cultura de Izquierdas en Argentina, Buenos Aires.

-"Reflexiones para la construcción de una alternativa peronista montonera auténtica", 9 de junio de 1979, en Centro de Documentación e Investigación de la Cultura de Izquierdas en Argentina, Buenos Aires.

- Resolución Nro 045/79, "Sobre la deserción de cinco militantes del partido y cuatro milicianos en el exterior", 10 de marzo de 1979, http://www.cedema.org.

Entrevistas

Testimonios que me brindaron ex militantes, con fechas 19/05/2011, 02/06/2011, 08/06/2011, 15/07/2011, 29/08/2011, 24/11/2011, 19/04/2012, 27/09/2016 у 13/10/2016. 